Running header: Autism intervention research

\title{
Piloting autism intervention research with teachers in mainstream classrooms
}

Libby Macdonald $^{1,5}$, Deb Keen ${ }^{1,5}$, Jill Ashburner ${ }^{2,5}$, Debra Costley ${ }^{4,5}$, Kaaren Haas $^{4,5}$ and David Trembath ${ }^{3,5}$

${ }^{1}$ Autism Centre of Excellence, School of Education and Professional Studies, Griffith

University

${ }^{2}$ Autism Queensland

${ }^{3}$ Menzies Health Institute, Griffith University

${ }^{4}$ Autism Spectrum Australia (Aspect)

${ }^{5}$ Cooperative Research Centre for Living with Autism

Address correspondence to Deb Keen, Autism Centre of Excellence, Department of Education and Professional Studies, Griffith University, Messines Ridge Road, Mt Gravatt, Brisbane, 4122, Australia. Email: d.keen@griffith.edu.au

Acknowledgments

The authors acknowledge the financial support of the Cooperative Research Centre for Living with Autism (Autism CRC), established and supported under the Australian Government's Cooperative Research Centres Program. This work was also supported by the Griffith Institute for Educational Research. David Trembath is supported by a NHMRC ECR Fellowship (GNT1071811). 


\begin{abstract}
Although there is a recognised need for effective practices to support students on the autism spectrum in mainstream schools, there is a research to practice gap in the area of autism and education, whereby evidence-based intervention may take decades to translate into mainstream classroom practice. Thus, current recommendations are that, rather than presenting mainstream school teachers with interventions developed and tested in clinical or special education settings, a participatory research process should be used to facilitate implementation in real-world mainstream classrooms. This paper reports on a case study that aimed to refine a structured teaching intervention package for use in mainstream classrooms, while at the same time tailoring research methods for evaluating the package in these settings. The outcomes of the project are presented with respect to (a) the development and refinement of the intervention package in consultation with a mainstream classroom teacher and (b) the lessons learned during the process that other clinical researchers, teachers, and clinicians could apply when implementing educational interventions in mainstream settings.
\end{abstract}

Keywords: autism spectrum disorder, structured teaching, research to practice gap, mainstream classrooms, teachers, educational interventions, messy research 
With rises in the number of children diagnosed as being on the autism spectrum (Australian Bureau of Statistics 2014, Elsabbagh et al. 2012), and a move towards more inclusive approaches to education (UN General Assembly 2007, Leach and Duffy 2009), there is an increasing challenge to meet the needs of students on the autism spectrum enrolled in mainstream schools. In fact, in Australia, approximately $73 \%$ of students on the spectrum are enrolled in mainstream schools (Autism Awareness 2014), and there is an identified need for practical ways to support the inclusion and optimise the learning outcomes of these students within mainstream settings (Saggers 2015).

The school environment can be very challenging for students on the autism spectrum who have difficulty with aspects of typical social interaction and communication, a preference for predictability and routine, resistance to change, and/or atypical reactions to sensory stimuli (American Psychiatric Association 2013). School can be a source of considerable stress and anxiety for these children and may contribute to difficulties in engaging with the curriculum and in self-regulation (Ashburner, Ziviani, and Rodger 2010, Humphrey and Lewis 2008). Teachers too, face challenges in this environment, tasked as they are with supporting the learning needs of students on the spectrum as well as numerous other students with diverse learning needs.

\section{Translating research to classroom settings}

Teachers in mainstream settings play a key role in supporting students on the autism spectrum to participate at school (Humphrey and Symes 2013), but research has indicated that teachers may feel ill-equipped to support the learning and development of these students (Emam and Farrell 2009, Soto-Chodiman et al. 2012). Furthermore, transferring teaching strategies that have been reported to be effective in clinical and special school environments directly to a mainstream school setting, without any adaptations, can be problematic. Interventions that have been shown to work under controlled research conditions are not 
necessarily as effective, or relevant, in the less controlled and less predictable classroom environment (Kasari and Smith 2013, Parsons et al. 2013). Additionally, the implementation of an intervention may not be practical for everyday classroom practice due to restrictions in time or resources, or may single out, and therefore stigmatise, students on the spectrum in ways that are inconsistent with inclusive classroom practices (Jordan 2008, Humphrey and Lewis 2008).

\section{Addressing the research-practice gap through participatory research}

Participatory research has gained popularity in the area of health as an approach with the potential to bridge the gap between science and practice (Cornwall and Jewkes 1995, Wallerstein and Duran 2010). To help close the research to practice gap in mainstream education for students on the autism spectrum and arrive at feasible and socially valid solutions to improve the educational experience and outcomes for these students, research needs to take place within mainstream classroom contexts, and should incorporate the goal of implementation, and participation of stakeholders (e.g., teachers, students) in the research process (Dingfelder and Mandell 2011, Dykstra Steinbrenner et al. 2015, Kasari and Smith 2013, Nastasi et al. 2000). Accordingly, some researchers have recommended a move away from controlled testing of interventions intended for applied settings, suggesting instead that development and evaluation take place primarily in situ (Kasari and Smith 2013, Weisz 2000). However, research methods that are commonly adapted to applied classroom settings may not be regarded as sufficiently rigorous to provide generalizable evidence (Barab and Squire 2004, Dykstra Steinbrenner et al. 2015) and the "noise" of the classroom makes it challenging to gather clean experimental data rendering effects more difficult to interpret (Kasari and Smith 2013).

\section{A case study in participatory research}

This article describes a case study used to refine standard experimental research methods for 
use in a mainstream setting during which the "noise" of the classroom environment was evident. This case study, and a companion study employing a multiple baseline research design and using the case study findings (manuscript in preparation), contributed to a research project that aimed to develop and implement a teacher-mediated intervention incorporating two structured teaching strategies: visual schedules and work systems. Visual schedules consist of concrete items, pictures, symbols, or words that convey an idea of the order of events to come (e.g. a daily timetable) (Hume 2015, Knight, Sartini, and Spriggs 2014). The use of visual schedules to support students on the autism spectrum has been researched extensively and is now considered to be an evidence-based practice (Knight, Sartini, and Spriggs 2014, National Autism Center 2015, Wong et al. 2015) Work systems are defined as ways of visually organising activities so that students are informed of what task to do, how much work is expected, how to know it is finished, and what to do next (Hume and Odom 2007, Howley 2015, Mesibov, Shea, and Schopler 2004). A small number of studies have focussed on work systems and have indicated that they may help students on the spectrum to stay on-task, and transition between tasks, with greater independence (Hume, Plavnick, and Odom 2012, Mavropoulou, Papadopoulou, and Kakana 2011, Hume and Odom 2007, O'Hara and Hall 2014, Bennett, Reichow, and Wolery 2011).

Despite the promising findings of previous studies however, these strategies are not routinely used in mainstream classrooms. There is little research to support their use in the mainstream context (Hume, Plavnick, and Odom 2012, O'Hara and Hall 2014) and none examining their use as teacher implemented strategies with a whole-class approach. If such strategies prove effective in mainstream settings, they could potentially reduce the amount of time teachers spend assisting individual students, and help to improve educational outcomes. Evaluating these strategies in an ecologically valid way, however, involves reconciling a need 
for experimental control with the task of measuring the effect of an intervention in a context where experimental control is lacking.

\section{Case study aims}

The first aim of this study was to consult with a classroom teacher to refine a structured teaching intervention package for use in mainstream classrooms, and establish a method for evaluating its effectiveness in preparation for the subsequent multiple baseline study. This approach was chosen in an attempt to address the persistent research to practice gap in the area of autism and mainstream education (Parsons et al. 2013, Dingfelder and Mandell 2011) by adopting a participatory approach to engage with stakeholders (Nastasi et al. 2000, Kasari and Smith 2013). It was considered that involving teachers in implementing and evaluating the teaching strategies and testing their effectiveness in a mainstream school environment would increase the likelihood of developing an intervention that was workable in the real-life classroom setting, because, as described by Parsons (2013), this would facilitate a process of "knowledge exchange" between stakeholders, rather than merely "knowledge transfer" (p. 277).

The second aim of the case study was to document the process and outcomes so as to inform the practice of researchers, clinicians, and educators who seek to implement similar intervention packages in mainstream school settings. Accordingly, this article presents not a direct evaluation of the strategies themselves, but reflections on the process of preparing to conduct empirical research in the natural classroom environment, and the challenges that can entail. Insights about this process are often not included in accounts of research outcomes, despite the growing recognition of the need for research that more closely facilitates implementation. 


\section{Method}

\section{Research design}

The case study method was used as part of a research process with a focus on implementation. While a case study design may not lead to reliable generalisations, it can illuminate the detail of a specific situation and highlight the complexity of the environment. Case studies have been recommended where the phenomenon under investigation is inseparable from its context, or where experimental control of context is not possible (Yin 2014). In this case, the unit of analysis was the interaction between research practice and the complex context of the mainstream classroom setting. It was therefore considered the most appropriate method to achieve the aims of this study.

\section{Ethics}

Ethical clearance for this project was obtained from the authors' universities and the relevant state educational authority.

\section{Participants}

The first author approached the principal of a local primary school and informed her about the research. The principal then identified a teacher, Mr Smith (a pseudonym), who was keen to participate, and he, in turn, identified a student on the autism spectrum for whom he believed the planned intervention could be useful. The principal, Mr Smith, other teachers working in the classroom, the student, and the student's parents all formally consented to participate in the study.

The student, Ben (a pseudonym) was diagnosed with Asperger Disorder (American Psychiatric Association 2000) by a paediatrician at the age of six years, and was described by his parents as 'high functioning.' At the time of this study he was nine years old and in Year 3 in a Year 3-4 composite class (i.e., comprising students from both year groups). Mr Smith reported that Ben was reluctant to engage with school work and was slow to start classroom 
activities, despite being capable of completing the work. The Kaufman Brief Intelligence Test, second edition (KBIT-2; Kaufman and Kaufman 2004) was used to provide an indication of academic ability, and Ben scored within the average range. Ben's off-task behaviour was confirmed by the first author during initial classroom observations. To illustrate, Ben was usually the last student to enter the room after breaks, up to five minutes after his classmates. Despite receiving the same directions as his peers, Ben often did not start work immediately, but played with objects, sharpened pencils, or sat at his desk not engaged in any specific learning activity.

\section{Setting}

Ben's school was a small regional public primary school (Grades Prep to Year 6) of 114 students. The school rated at 937 on the Index of Community Socio-Educational Advantage (ICSEA) developed by the Australian Curriculum, Assessment and Reporting Authority (ACARA 2014), a rating which is below the national average of 1000. The class consisted of 20 students - 13 male and 7 female - in Years 3 and 4 aged between eight and ten years, and, according to their teacher, encompassed a wide range of academic ability. Ben was one of four students in the class with diagnoses on the autism spectrum.

Mr Smith's class was managed using routines that he had established early in the school year and a school-wide point system that rewarded positive behaviour. He used various approaches to accommodate the range of abilities within the class, including the use of highly scaffolded lessons; different activities for different students or year levels; and because there were often up to three teacher aides or support staff in the class, one-to-one or small group pull-out activities. The literacy and numeracy lessons in class were generally taken directly from the government curriculum documents, with worksheet questions being completed one at a time as a whole class activity. Prior to commencing this case study, the 
classroom had a daily visual schedule on the board; however, it was not regularly updated by the teacher and was not always accurate.

\section{Intervention and materials}

The participatory design of the study required the teacher, Mr Smith, to develop an intervention that would help Ben (and possibly other students in the class) to stay on-task and transition between tasks independently, so that this intervention could then be trialled and refined during this study. To support Mr Smith with this task, the study used a workbook specifically designed for this study (Haas, 2015). The workbook was designed to guide mainstream classroom teachers to develop and implement two aids for use by the whole class: a visual schedule in the form of a daily timetable and a work system for a literacy task. The workbook contained an explanation of structured teaching principles, including the proposed benefits of using visual structure, links to online information, and guidance and examples on how to develop a daily timetable and a visually-organised literacy task. To supplement this, the researcher also showed Mr Smith pictures of three other examples of different types of work systems - a carrel with numbered drawers and symbols, a folder system with "to do" and "finished" pockets, and a checklist with checkboxes, and gave the teacher an optional template for a checklist. The materials used to deliver the intervention were left to Mr Smith's discretion. The intervention was intended to be deliverable with the

simplest, low-tech equipment (i.e. pencil and paper), but there was scope to use technology if it was available.

Mr Smith chose to devise his own checklist format, which conformed to the definition of a work system by visually conveying information about what task to do, how much work was expected, how to know it was finished, and what to do next (Hume and Odom 2007, Howley 2015, Mesibov, Shea, and Schopler 2004). Using the teacher's own class schedule, the first author reproduced timetables, and all students in the class were given a choice of a 
weekly timetable that could be stuck to their desks or an A5 booklet of daily timetables for the week. During the course of the study, to provide both guidelines for applying the strategies in the classroom and a measure of fidelity, the researcher developed and refined an implementation checklist based on the defining characteristics of visual schedules and work systems.

\section{Procedure}

The first author met with the school principal and Mr Smith early in the third school term to outline and discuss the purpose of the case study. Then, during the first half of the term, the first author spent a total of four full days making preliminary, informal observations, getting to know the classroom routines and procedures, and, when Mr Smith's schedule permitted, consulting with him to obtain his input on task selection and selection of behaviours (i.e., dependent variables) that would be monitored as part of the intervention evaluation.

\section{Selecting tasks.}

The first author consulted with Mr Smith about the types of activities, subjects and circumstances during which Ben seemed to have the most difficulty staying on-task. The first author then explained to Mr Smith that, from these, it was necessary to select a task, or set of tasks, to observe that would be repeated consistently throughout the study, so as to measure change over time. To assess effects on Ben's independence while working, the task also needed to be one that could be done independently, and so would likely involve practising and reinforcing skills with which Ben was already familiar, rather than introducing completely new learning tasks. To provide an ecologically valid context and avoid causing inconvenience to Mr Smith and his class, Mr Smith was asked to identify suitable regular class tasks.

A handwriting task that regularly took place after a break met these criteria. In this task, students were required to write several lines of letters from the alphabet. The first author 
observed that, because the class were working on a longer written composition over a number of weeks, there was then a regular transition to the computers where students typed out previously finished written work. The typing activity was also selected as an appropriate task to observe for the study.

\section{Identifying dependent variables.}

Visual schedules and work systems have been shown to promote on-task behaviour, reduce problem behaviours, and to increase students' independence (Knight, Sartini, and Spriggs 2014, Hume and Odom 2007, Bennett, Reichow, and Wolery 2011, Lequia, Machalicek, and Rispoli 2012). To identify appropriate measures that could be used to assess Ben's productivity, or his attention to task, before and after the introduction of the intervention, $\mathrm{Mr}$ Smith was further consulted about Ben's behaviour. Two types of behaviours were chosen to be coded and measured: (a) behaviours associated with being on-task, or getting work done, and (b) problem behaviours associated with not engaging with the set activity. Mr Smith's input in identifying these "off-task" type behaviours was particularly valuable as these can be highly individual and context specific. Other dependent variables chosen to be recorded by observation were: teacher prompting as a measure of student independence; the time Ben took to start work, (or latency); and the amount of work Ben completed.

On-task. The first author communicated with Mr Smith about his expectations of Ben during the selected tasks. Task specific on-task behaviours were then identified and defined through the first author's observations of Ben at work. For the handwriting task, on-task behaviour was defined as holding a pencil such that the tip was touching the page. While on the computer, Ben was considered on-task when pressing a key on the keyboard. Mouse clicks were not coded as observations by the first author noted that these did not specifically contribute to completing the work that Mr Smith had indicated Ben was supposed to be doing (i.e. typing up his written work). 
Problem behaviour. To accurately reflect what Ben was doing when not on-task, Mr Smith was asked about behaviours he had noticed occurring at times when Ben was having difficulty attending to work. Problem behaviours were defined to include yelling, lying on the ground, throwing objects, hitting, or running out of the room. These behaviours have been similarly described in several other studies examining the use of visual supports (Mavropoulou, Papadopoulou, and Kakana 2011, Waters, Lerman, and Hovanetz 2009, Dooley, Wilczenski, and Torem 2001). However, although these behaviours may occur in mainstream classrooms, they tend to be behaviours that occur infrequently and may not provide a sensitive measure. Mr Smith observed that behaviours that corresponded with time off-task included Ben being out of his chair, playing with toys, sharpening pencils. Accordingly, these behaviours were defined and observed.

Additional measures. In addition to the dependent variables that were defined with input from Mr Smith, the research team used a number of other measures to support the direct observational data and provide a more complete account of changes that occurred during the intervention.

Response latency. The time on the classroom clock was recorded at the moment Ben entered the classroom, and this was also when observations commenced. Calculations were then made to record the time between the start of class, Ben entering the class, and Ben's first instance of on-task behaviour.

Productivity. In addition to recording on-task behaviours, productivity was measured by assessing the amount of work Ben completed during the first 10 minutes of the task. During the handwriting task, a count was made of the number of lines written, and, during work at the computer, the number of words typed were counted. 
Teacher perception of productivity. During the course of the study, the research team developed a new measure whereby Mr Smith could indicate daily, on a scale from 1-10, how productive he thought Ben had been in comparison to his expectations of the class. This measure was trialled during the case study.

Teacher prompting. Previous studies have used the level of teacher prompting (i.e. the number of intervals during which prompting occurs) as a measure of change in student independence when transitioning to tasks (Hume and Odom 2007, Hume, Plavnick, and Odom 2012, Mavropoulou, Papadopoulou, and Kakana 2011). In this study, the research team collected data on Mr Smith's interactions with Ben to provide information about the amount of assistance or direction required by Ben and the amount of time spent by the $\mathrm{Mr}$ Smith in supporting him. This was done without consultation with Mr Smith, so as to capture natural behaviours.

Social validity. To assess their perceptions of the value and practicality of the teaching strategies, at the end of the intervention phase both Ben and Mr Smith completed surveys developed for this study. The surveys consisted of both Likert-type and open questions. The teacher survey was provided via email as a digital file to be completed at Mr Smith's convenience. It included questions about the effectiveness of the two structured teaching strategies, the ease with which they could be implemented, and asked for feedback on the workbook. The student survey was conducted in the form of a brief interview in which the first author read the questions to the student and wrote down his responses.

\section{Evaluating the intervention}

$\mathrm{An} A B$ single case experimental design was used to assess the feasibility of the research methods, and collect preliminary data on the effectiveness of the intervention strategies. 
The first author trialled data recording procedures during both the handwriting and typing tasks. Not only did this allow observations of student behaviours during class activities, but it was also possible to gather information about latency during transitions into and between tasks. The first author continued to visit the class four times per week over a period of five weeks After the initial six sessions, the first author provided Mr Smith with a hard copy of the intervention workbook on a Friday and emailed a digital copy to him later the same day. He began to use a work system in the form of a simple checklist on the following Monday. The first author then continued to trial data collection with the intervention in place.

\section{Data collection.}

Other studies investigating the effect of work systems on student productivity and on-task behaviours have used video recording as a data collection method (Hume and Odom 2007, Hume, Plavnick, and Odom 2012, Bennett, Reichow, and Wolery 2011, Mavropoulou, Papadopoulou, and Kakana 2011). This research team had three key concerns about videorecording in the mainstream classroom. First, that permission would be necessary from nontarget children who would likely be captured during filming and this also led to concerns to protect their privacy; second, that the focus on filming Ben may have stigmatised him; and third, because video-recording may have made students and teachers more self-conscious about their behaviour, it may have artificially influenced their behaviour (Schuck and Kearney 2006). The research team therefore concluded that the case study was an opportunity to trial the feasibility of live data collection using partial interval recording of on-task and problem behaviours and teacher prompting. When taking observations, the research team took particular care to ensure that neither Ben, nor other students in his class, became aware that Ben was the subject of particular attention. Observations were usually taken from the back of the classroom or while circulating among the whole class. 
Inter-rater reliability was also trialled with a trained secondary observer. Sessions with the second observer involved using a double adapter for a digital audio player so that both observers could synchronise the intervals during which they made their observations by listening to the same audio cues. There was agreement between observers for on- and off-task behaviours in $90.39 \%$ and $90.15 \%$ of intervals respectively, and, for teacher prompting, there was agreement in $87.18 \%$ of intervals.

\section{Findings}

The data collected during the course of the case study was not intended to evaluate the intervention, but rather to develop, refine and trial methods and measures. The intervention was evaluated during the subsequent multiple baseline study with other teachers and students (manuscript in preparation). Thus, the findings of this study can be summarised as follows.

\section{Intervention}

This case study informed the refinement of the intervention package by providing a demonstration of its interpretation and application in a real-world setting, and an opportunity to obtain feedback from key stakeholders. As a result, the team made a number of adaptations to the workbook (Haas 2015), such as including supplementary information on visual schedules and work systems that had been provided to Mr Smith by the first author, and that he reported finding useful (i.e. additional visual examples of ways work systems could be used) and an implementation checklist to help teachers to implement the strategies. The feedback Mr Smith provided on his survey also indicated areas in which the intervention could possibly benefit from further refinement as the project progressed.

\section{Task selection}

The choice of a class activity to focus on, that was both an authentic classroom practice as well as a reliable constant during observations, was a key factor in combining a quantitative $\mathrm{AB}$ research design with the qualitative case study approach that would be sensitive to the 
complex classroom conditions. Task selection in consultation with the teacher was demonstrated to be a feasible way to work within a mainstream classroom setting, and to capture data in an ecologically valid way.

\section{Identifying and defining measures}

Identifying target behaviours with input from Mr Smith allowed measures to be created that were nuanced and individualised with respect to Ben in particular as well as being relevant to the Mr Smith's expectations and classroom culture as a whole. The process used to identify behaviours, involving both direct input from the Mr Smith and consultation to confirm additional observations by the first author, provided relevant and clearly defined measures.

\section{Social validity}

On the social validity survey, Ben indicated that he found the timetable to be of some help, and the work system to be very helpful. He expressed a willingness to keep using both strategies. Mr Smith reported that the timetables were very useful and easy to implement. He indicated that the work systems were very helpful in keeping the student on the autism spectrum on-task and also helpful for some of the other students in the class. However, his feedback was that he would not recommend it as a whole-of-class intervention, due to the time required to develop the task checklists to his satisfaction for multiple students with diverse abilities.

\section{Data collection}

This case study was instrumental in refining and practicing data collection methods that were intended to be unobtrusive and sensitive to the classroom context. While the class was accustomed to the presence of other adults in the room, such as teacher aides and parent volunteers, regular visits to become familiar with the class prior to the data collection phase minimised the impact of the first author's presence and allowed for monitoring of any apparent changes in Ben's behaviour when observations began. Making observations while 
seated at the back of the classroom, or while circulating and scanning the entire class also helped to minimise the impact of an observer in the classroom. Reliability measures indicated that data could be collected live in this way with acceptable levels of accuracy.

\section{Discussion}

In preparing to conduct empirical research in a mainstream classroom environment, this case study provided a way to test and refine a teacher-implemented intervention. Furthermore, it provided a way for research procedures to be designed, refined, and modified to fit the classroom context. This case study provided a logical step in an iterative research process, and one that might increase the relevance of research to applied settings. In this particular case, the case study was influential in devising ways to better fit both the research procedures and intervention to the context. It highlighted a number of potential issues that, with preparation, could be managed or addressed.

\section{Advantages of piloting in the classroom}

In this case study, tasks were selected, and dependent variables defined, in consultation with the teacher, using tasks already undertaken by the student as part of current class activity, and observing behaviours occurring naturally in the classroom. This approach allowed the research design to be tailored to specific classes and individuals rather than developing a task specifically for the purpose of the research or looking for generic behaviours. In this case, the handwriting task was practised by the whole class as a transition activity to reinforce a familiar skill, and the typing activity was part of a longer writing task. This method of getting to know the class and working with teachers to make decisions about the way the research will be conducted can also be applied to other classes, as a means of ensuring that research in the classroom is ecologically valid. Similarly, the process used to identify dependent variables that are relevant to the teacher and student can lead to measures that are highly specific and individual. Patterns of disruptive behaviour noted by teachers can be targeted, 
even though in other contexts, or for other individuals, they may not be considered problematic.

There are precedents for researchers working with teachers to identify and address individual needs in students on the spectrum. Hume et al. (2012), for example, consulted with their subjects' special education teacher to identify appropriate tasks to focus on, and other researchers have targeted individual behaviours in consultation with teachers and parents (Cale et al. 2009, Cihak et al. 2009). It is less common, however, for empirical studies to fit around the culture of a mainstream classroom. However, tailoring research to the mainstream classroom, rather than simply an individual within this setting, could be an important step in developing interventions that can be implemented in an inclusive way by mainstream teachers. By observing natural activity and supporting teachers to identify and define behaviours they consider important to change, it is possible to create a research design that is more relevant to teachers' understanding of the unique characteristics of their class and the outcomes they wish to achieve for their students. For teachers, the conceptualisation of research as a practice that can fit within the classroom environment may facilitate more teacher-driven, or teacher-implemented evaluations of interventions. Such an approach could contribute to bridging the research to practice gap by involving stakeholders in the research to practice process in a fundamental way (Nastasi et al. 2000).

For researchers, tailoring a study to fit the classroom, rather than attempting to engineer controlled conditions, may be beneficial in offering practical, ecologically valid approaches to evaluating interventions. In this case study, the development and testing of data collection procedures in the classroom was not only feasible, it also resulted in a strong alignment between the research design and the environment. Whereas taking a student from the classroom to a more controlled environment is likely to have an effect on the student's behaviour and responses to an intervention, classroom data collection can provide insights 
into whether an otherwise effective treatment is worth applying in a real-world context. If it is possible to minimise the impact of the researcher in the classroom through frequent visits and unobtrusive observation techniques, as described above, it may be possible to capture more authentic and relevant behavioural responses. Pilot testing of the data collection method can be helpful in ensuring that it is workable. In this case, the pilot-testing of live data recording confirmed that the presence of the researcher in the room was not a distraction, and was in many ways preferable to video-recording. The data collection method was also demonstrated to be reliable through inter-rater observations on all the central measures. Furthermore, reliability improved as methods were refined.

While examination of the observational data may give an indication of the efficacy of an intervention, if those for whom it was intended do not perceive it as useful, or see barriers to implementation, then it would be difficult to regard the intervention as a success. Although social validity measures have been considered to be an essential aspect of experimental rigour (Reichow, Volkmar, and Cicchetti 2008), Howley (2015) identified the social validity of structured teaching strategies as an area where quantitative methods have limitations, and a more thorough, in-depth analysis is needed. Feedback provided on an intervention trialled in the classroom during normal lessons, and implemented by teachers using materials available to them, is informed by relevant experience. Social validity measures in studies such as this may link research to implementation more closely than features of research design focussed on producing quantitative data about behavioural outcomes.

The social validity surveys for this study revealed positive attitudes about the use of the strategies in supporting Ben to stay on-task. However, as mentioned earlier, Mr Smith reported some difficulties with adapting the intervention for the whole class. While classroom diversity and the composite nature of Mr Smith's class may have been contributing factors to 
the decision in his particular circumstances, this feedback highlighted issues pertaining to the development of resources following universal design principles. A broader study of teacher perceptions would be required to ascertain whether the time taken to implement a whole of class intervention was a common concern.

\section{Challenges and recommendations}

This case study encountered a number of difficulties that are commonly experienced in school environments. The most significant was the interruption during the intervention phase due to the absence of Mr Smith due to injury. During his absence, a relief teacher, Ms Hall (a pseudonym), was appointed to take his class. Ms Hall did not consistently implement the intervention, despite expressing an interest in the research and the strategies. The class was challenging at times, and she was an experienced teacher with her own collection of strategies and resources. During this time, Ben, and others, became very concerned with small changes made by Ms Hall to their timetable and routine, and corrected her if activities did not proceed in the correct order. Data collection became challenging, because the set tasks were not always performed at the same time, and routines surrounding entering the class and starting work changed. These challenges were, however, instructive in demonstrating differences in teaching styles and classroom practices and the marked effect these can have on research in the natural classroom setting.

Ben was also absent from school for a number of days due to illness. Interruptions such as these are a potential challenge in real world settings. Unpredictable events in teachers' and students' lives can make it difficult to link the introduction of the intervention to any changes in the student's behaviour. These absences made it difficult to collect the necessary observational data prior to the end of term. Overall, a major challenge in conducting research within schools is the need to fit around school terms, special events and holidays. The first and last week of each term may be atypical and impact student behaviour. 
The beginning and end of the school year can be particularly disruptive as students settle in or prepare to transition to new classes. Researchers are therefore advised to time their classroom visits carefully, allowing extra time for unexpected interruptions, or including more participants, and consulting with teachers and school administration about special events when developing their research design.

This case study served both as a way to refine an intervention for practical use and an informative experience from which to reflect on the way research may be undertaken in a naturalistic setting. The experience of continual and unplanned disruptions to class time typifies many mainstream school settings, and it is possible that these disruptions actually contribute to some of the challenges faced by students on the autism spectrum. As Flannery and Horner (1994) observed, "natural school environments are not consistent, thereby forcing teachers to choose between including the student in inconsistent, regular school activities or providing the student with highly consistent, but more isolated educational options" (p.158). The concerted use of structured teaching strategies, which prepare students for upcoming changes and provide greater structure to individual activities, may be useful in ameliorating the unavoidable disruptive nature of the typical mainstream school setting. However, a rigorous empirical examination of the implementation of these strategies would traditionally call for a significant amount of environmental control, resulting in high levels of predictability and structure. From this observation, two conclusions may be drawn. First, researchers may find the mainstream school environment challenging in very similar ways to students with on the autism spectrum. Second, an in situ evaluation of this type of intervention may not be possible without using flexible methods that take account of the inconsistencies and unpredictability of the school environment.

During the course of conducting this case study it was possible to identify, and deal with, potential issues with the data. There were, for instance, some difficulties with 
consistently collecting data on student productivity due to the varying length of the task and due to frequent, often externally driven interruptions to the student's work (e.g., a visitor to the classroom). This led to the development and trialling of an additional measure where the teacher was asked to rate the student's productivity at the end of each session. This measure served to quantify the teacher's views of the intervention's effect and provided another flexible measure of child behaviour. Without trialling and adapting methods in this way, the larger study would have relied on measures that may not have been appropriate in the real classroom context.

Aside from helping to refine methods and engage teachers, piloting research procedures can also be recommended so that researchers approach larger scale studies in schools forewarned, or so that teachers and therapists trialling interventions in situ can evaluate them with greater accuracy. This study highlighted the need for contingency plans, such as increasing the number of participants to protect against attrition due to participant absences, or other unforeseen circumstance. Sports and swimming carnivals, camps, rescheduling of non-contact time, reporting, professional development, visiting speakers, excursions, and many other events clamour for a place in the school calendar, and working around these with sensitivity for teachers' time requires careful planning. A case study can help to increase awareness of the frequency of these events and the effect they have on school life and students on the spectrum in particular. Piloting can also be instrumental in arriving at operational definitions that can be modified and applied to fit unique individuals and changeable settings and form the basis of a flexible research design.

\section{Conclusion}

There is both an urgent need for interventions to support students on the autism spectrum in mainstream settings, and a widely acknowledged difficulty in translating research into educational practice (Dingfelder and Mandell 2011, Parsons et al. 2013). Although 
controlled studies are necessary to provide reliable data for isolated strategies without the interference of uncontrolled variables, the evidence that they provide is incomplete without testing and refining in an applied setting. It is, in part, the chaotic, unpredictable nature of the school environment that drives the need for intervention. If it were possible to create classroom conditions that were suitably controlled, perhaps the need for educational interventions for students on the spectrum would be less urgent. However, as controlled classroom environments are unlikely to be attainable in mainstream schools, research in this context is bound to be messy yet essential to the development, assessment and implementation of interventions.

As considerations of implementation become increasingly part of research into interventions for children on the spectrum, rather than a secondary process (Dykstra Steinbrenner et al. 2015), there may be a need to further adapt experimental research methods to the school environment and to foster a culture of research participation among educators. Clearly, there is more work to be done in this area. While researchers are feeling their way, the use of a single case trial like this one can be recommended. Case studies like this one may be instrumental in forwarding discussion about ways in which individual research projects can be tailored to educational settings, framing questions of validity, and preparing researchers for the many possible challenges that they may encounter. 
References:

American Psychiatric Association. 2000. Diagnostic and Statistical Manual of Mental Disorders (4th Ed., Text Rev.). Washington, DC: American Psychiatric Publishing.

American Psychiatric Association. 2013. Diagnostic and Statistical Manual of Mental Disorders (5th Ed). Arlington, VA: American Psychiatric Publishing.

Ashburner, Jill, Jenny Ziviani, and Sylvia Rodger. 2010. "Surviving in the Mainstream: Capacity of Children with Autism Spectrum Disorders to Perform Academically and Regulate Their Emotions and Behavior at School." Research in Autism Spectrum Disorders 4 (1):18-27. doi: 10.1016/j.rasd.2009.07.002.

Australian Bureau of Statistics. 2014. Autism in Australia, 2012.

Australian Curriculum, Assessment and Reporting Authority (ACARA). 2014. "Guide to Understanding 2013 Index of Community Socio-Educational Advantage (Icsea) Values."

Autism Awareness. 2014. \#Autism2014: A National Survey of Autism Parents and Carers. Summary Report.

Barab, Sasha, and Kurt Squire. 2004. "Design-Based Research: Putting a Stake in the Ground." The Journal of the Learning Sciences 13 (1):1-14.

Bennett, Katherine, Brian Reichow, and Mark Wolery. 2011. "Effects of Structured Teaching on the Behavior of Young Children with Disabilities." Focus on Autism and Other Developmental Disabilities 26 (3):143-152. doi: 10.1177/1088357611405040.

Cale, S. I., E. G. Carr, A. Blakeley-Smith, and J. S. Owen-DeSchryver. 2009. "Context-Based Assessment and Intervention for Problem Behavior in Children with Autism Spectrum Disorder." Behavior Modification 33 (6):707-42. doi: 10.1177/0145445509340775.

Cihak, D., C. Fahrenkrog, K. M. Ayres, and C. Smith. 2009. "The Use of Video Modeling Via a Video Ipod and a System of Least Prompts to Improve Transitional Behaviors for Students with Autism Spectrum Disorders in the General Education Classroom." Journal of Positive Behavior Interventions 12 (2):103-115. doi: 10.1177/1098300709332346.

Cornwall, Andrea, and Rachel Jewkes. 1995. "What Is Participatory Research?" Social Science \& Medicine 41:1667-1676.

Dingfelder, Hilary E, and David S Mandell. 2011. "Bridging the Research-to-Practice Gap in Autism Intervention: An Application of Diffusion of Innovation Theory." Journal of Autism and Developmental Disorders 41:597-609. doi: 10.1007/s10803-010-1081-0. 
Dooley, P., F. L. Wilczenski, and C. Torem. 2001. "Using an Activity Schedule to Smooth School Transitions." Journal of Positive Behavior Interventions 3 (1):57-61. doi: $10.1177 / 109830070100300108$.

Dykstra Steinbrenner, J. R., L. R. Watson, B. A. Boyd, K. P. Wilson, E. R. Crais, G. T. Baranek, M. Flippin, and S. Flagler. 2015. "Developing Feasible and Effective School-Based Interventions for Children with Asd: A Case Study of the Iterative Development Process." Journal of Early Intervention 37 (1):23-43. doi: 10.1177/1053815115588827.

Elsabbagh, M., G. Divan, Y. J. Koh, Y. S. Kim, S. Kauchali, C. Marcin, C. Montiel-Nava, V. Patel, C. S. Paula, C. Wang, M. T. Yasamy, and E. Fombonne. 2012. "Global Prevalence of Autism and Other Pervasive Developmental Disorders." Autism Research 5 (3):160-79. doi: 10.1002/aur.239.

Emam, Mahmoud M., and Peter Farrell. 2009. "Tensions Experienced by Teachers and Their Views of Support for Pupils with Autism Spectrum Disorders in Mainstream Schools." European Journal of Special Needs Education 24 (4):407-422. doi: 10.1080/08856250903223070.

Flannery, Brigid, K., and Robert H. Horner. 1994. "The Relationship between Predictability and Problem Behavior for Students with Severe Disabilities." Journal of Behavioral Education 4 (2):157-176. doi: 10.1007/BF01544110.

Haas, Kaaren. 2015. Helping Students in Mainstream Primary Classrooms Stay-on-Task and Transition between Tasks: Visual Schedules and Work Systems. A Workbook for Teachers. Autism Spectrum Australia (Aspect).

Howley, Marie. 2015. "Outcomes of Structured Teaching for Children on the Autism Spectrum: Does the Research Evidence Neglect the Bigger Picture?" Journal of Research in Special Educational Needs 15 (2):106-119. doi: 10.1111/1471-3802.12040.

Hume, Kara. 2015. "Structured Teaching Strategies: A Series." Indiana Resource Center for Autism. http://www.iidc.indiana.edu/?pageld=3520.

Hume, Kara, and Sam. Odom. 2007. "Effects of an Individual Work System on the Independent Functioning of Students with Autism." Journal of Autism and Developmental Disorders 37:1166-80. doi: 10.1007/s10803-006-0260-5.

Hume, Kara, Joshua Plavnick, and Samuel L. Odom. 2012. "Promoting Task Accuracy and Independence in Students with Autism across Educational Setting through the Use of Individual Work Systems." Journal of Autism and Developmental Disorders 42:2084-99. doi: 10.1007/s10803-012-1457-4. 
Humphrey, Neil, and Sarah Lewis. 2008. "Make Me Normal'the Views and Experiences of Pupils on the Autistic Spectrum in Mainstream Secondary Schools." Autism 12 (1):23-46. doi: $10.1177 / 1362361307085267$.

Humphrey, Neil, and Wendy Symes. 2013. "Inclusive Education for Pupils with Autistic Spectrum Disorders in Secondary Mainstream Schools: Teacher Attitudes, Experience and Knowledge." International Journal of Inclusive Education 17 (1):32-46. doi: 10.1080/13603116.2011.580462.

Jordan, Rita. 2008. "The Gulliford Lecture: Autistic Spectrum Disorders: A Challenge and a Model for Inclusion in Education." British Journal of Special Education 35 (1):11-15.

Kasari, C., and T. Smith. 2013. "Interventions in Schools for Children with Autism Spectrum Disorder: Methods and Recommendations." Autism 17 (3):254-67. doi: 10.1177/1362361312470496. Kaufman, Alan S, and Nadeen L Kaufman. 2004. Kaufman Brief Intelligence Test - Second Edition (Kbit-2). Circle Pines, MN: American Guidance Service.

Knight, Victoria, Emily Sartini, and Amy D Spriggs. 2014. "Evaluating Visual Activity Schedules as Evidence-Based Practice for Individuals with Autism Spectrum Disorders." Journal of Autism and Developmental Disorders 45 (1):157-178. doi: 10.1007/s10803-014-2201-z.

Leach, Debra, and Mary Lou Duffy. 2009. "Supporting Students with Autism Spectrum Disorders in Inclusive Settings." Intervention in School and Clinic 45 (1):31-37. doi: 10.1177/1053451209338395.

Lequia, Jenna, Wendy Machalicek, and Mandy J. Rispoli. 2012. "Effects of Activity Schedules on Challenging Behavior Exhibited in Children with Autism Spectrum Disorders: A Systematic Review." Research in Autism Spectrum Disorders 6 (1):480-492. doi: 10.1016/j.rasd.2011.07.008.

Mavropoulou, Sophia, Eleni Papadopoulou, and Domna Kakana. 2011. "Effects of Task Organization on the Independent Play of Students with Autism Spectrum Disorders." Journal of Autism and Developmental Disorders 41:913-25. doi: 10.1007/s10803-010-1116-6.

Mesibov, Gary B, V Shea, and E Schopler. 2004. The Teacch Approach to Autism Spectrum Disorders. New York: Springer.

Nastasi, Bonnie K, Kristen Varjas, Stephen L Schensul, K Tudor Silva, Jean J Schensul, and Priyani Ratnayake. 2000. "The Participatory Intervention Model: A Framework for Conceptualizing and Promoting Intervention Acceptability." School Psychology Quarterly 15 (2):207-232.

National Autism Center. 2015. Findings and Conclusions: National Standards Project, Phase 2. Randolph, Massachusetts: Author. 
O'Hara, Meghan, and Laura J. Hall. 2014. "Increasing Engagement of Students with Autism at Recess through Structured Work Systems." Education and Training in Autism and Developmental Disabilities 49:568-575.

Parsons, S., T. Charman, R. Faulkner, J. Ragan, S. Wallace, and K. Wittemeyer. 2013. "Commentary-Bridging the Research and Practice Gap in Autism: The Importance of Creating Research Partnerships with Schools." Autism 17 (3):268-80. doi: 10.1177/1362361312472068.

Reichow, B., F. R. Volkmar, and D. V. Cicchetti. 2008. "Development of the Evaluative Method for Evaluating and Determining Evidence-Based Practices in Autism." Journal of Autism and Developmental Disorders 38 (7):1311-9. doi: 10.1007/s10803-007-0517-7.

Saggers, B., Klug, D., Harper-Hill, K., Ashburner, J., Costley, D., Clark, T., Bruck, S., Trembath, D., Webster, A. A., \& Carrington, S. 2015. Australian Autism Educational Needs Analysis - What Are the Needs of Schools, Parents and Students on the Autism Spectrum? Executive Summary. Cooperative Research Centre for Living with Autism, Brisbane.

Schuck, Sandy, and Matthew Kearney. 2006. "Using Digital Video as a Research Tool: Ethical Issues for Researchers." Journal of Educational Multimedia and Hypermedia 15 (4):447-463.

Soto-Chodiman, Rebecca, Julie Ann Pooley, Lynne Cohen, and Myra Frances Taylor. 2012. "Students with Asd in Mainstream Primary Education Settings: Teachers' Experiences in Western Australian Classrooms." The Australasian Journal of Special Education 36 (2):97-111. doi: 10.1017/jse.2012.10.

UN General Assembly. 2007. Convention on the Rights of Persons with Disabilities: Resolution Adopted by the General Assembly, 24 January 2007

Wallerstein, Nina, and Bonnie Duran. 2010. "Community-Based Participatory Research Contributions to Intervention Research: The Intersection of Science and Practice to Improve Health Equity." American Journal of Public Health 100 (S1):S40-S46.

Waters, M. B., D. C. Lerman, and A. N. Hovanetz. 2009. "Separate and Combined Effects of Visual Schedules and Extinction Plus Differential Reinforcement on Problem Behavior Occasioned by Transitions." Journal of Applied Behavior Analysis 42 (2):309-13. doi: 10.1901/jaba.2009.42-309.

Weisz, John R. 2000. "Agenda for Child and Adolescent Psychotherapy Research: On the Need to Put Science into Practice." Archives of General Psychiatry 57:837-838.

Wong, Connie, Samuel L Odom, Kara A Hume, Ann W Cox, Angel Fettig, Suzanne Kucharczyk, Matthew E Brock, Joshua B Plavnick, Veronica P Fleury, and Tia R Schultz. 2015. EvidenceBased Practices for Children, Youth, and Young Adults with Autism Spectrum Disorder. Chapel 
Hill: The University of North Carolina, Frank Porter Graham Child Development Institute, Autism Evidence-Based Practice Review Group.

Yin, Robert K. 2014. Case Study Research: Design and Methods. 5th ed. Thousand Oaks, CA: Sage publications. 